•研究报告・

\title{
中国红河地区董棕林乔木树种的 物种组成和地理亲缘关系
}

\author{
陈文红 ${ }^{1,4}$ 施济普 $^{2}$ 文 军 $^{3}$ 郭世伟 $^{1}$ 常艳芬 $^{2}$ 税玉民 $^{1,4^{*}}$ \\ 1 (中国科学院昆明植物研究所东亚植物多样性与生物地理学重点实验室, 昆明 650201) \\ 2 (中国科学院西双版纳热带植物园, 云南预腊 666303) \\ 3 (United States National Herbarium, Department of Botany, Smithsonian Institution, National Museum of \\ Natural History, Washington, DC, USA) \\ 4 (云南省喀斯特地区生物多样性保护研究会, 昆明 650201)
}

\begin{abstract}
摘要: 在中国和中南半岛的喀斯特地区, 董棕(Caryota obtusa)林是一类外貌醒目、物种多样和生境独特的植物群 落。由于其具有作为食物和用于园艺的潜在价值, 董棕在自然生境中越来越稀少。为了弄清董棕林的群落特征和 物种组成, 我们在云南红河地区的一个喀斯特峡谷选取 6 个群落样方研究了董棕群落的物种多样性。在每个 $20 \mathrm{~m} \times$ $20 \mathrm{~m}$ 样方中, 调查了胸径( $\mathrm{DBH}) \geq 4 \mathrm{~cm}$ 的乔木树种的胸径等生物学特征。通过相对多度、相对频度和相对显著度 计算出研究区董棕林群落中每个乔木树种的重要值, 确定了该群落的优势组成。一方面, 我们分别通过分布区类 型和自然地理单元两种地理分布样式来分析乔木树种的地理成分组成特点, 从而确定董棕林的地理联系; 另一方 面, 我们选择了群落中重要值排名前5位的乔木树种, 通过地理分布图的绘制, 分析比较了 5 个优势树种的地理分 布特点及其关系, 确定了所选取的研究群落在整个董棕分布区的地位。结果表明, 云南红河地区董棕林由67种乔 木树种组成, 群落名称可定为董棕+双果桑群落 (Caryota obtusa + Streblus macrophyllus community), 群落中乔木物 种的区系成分以中南半岛分布最多, 且是在热带东南亚喀斯特地貌大背景下发育形成的。研究暗示我国的董棕群 落已处于该类热带喀斯特植被的最北缘, 在中南半岛这个全球生物多样性热点地区值得优先加以保护。
\end{abstract}

关键词：热带北缘; 喀斯特峡谷; 棕榈科植物; 残存生境; 热带植被

\section{Composition and geographical affinity of the tree species Caryota obtusa forests in the Honghe region, SW China}

\author{
Wenhong Chen ${ }^{1,4}$, Jipu Shi ${ }^{2}$, Jun $\mathrm{Wen}^{3}$, Shiwei Guo ${ }^{1}$, Yanfen Chang ${ }^{2}$, Yumin Shui ${ }^{1,4^{*}}$ \\ 1 Key Laboratory for Plant Diversity and Biogeography of East Asia, Kunming Institute of Botany, Chinese Academy of \\ Sciences, Kunming 650201, China \\ 2 Xishuangbanna Tropical Botanical Garden, Chinese Academy of Sciences, Mengla, Yunnan 666303, China \\ 3 United States National Herbarium, Department of Botany, Smithsonian Institution, National Museum of Natural His- \\ tory, Washington, DC, USA \\ 4 Karst Conservation Initiative of Yunnan, Kunming 650201, China
}

\begin{abstract}
Caryota obtusa forests are characterized as showy vegetation with rich species diversity and a unique habitat in the Honghe region of China. Due to its food and horticulture value, mature Caryota obtusa individuals have become more rare in the field. Here, we sampled six plots in a deep karst valley of the Honghe region of Yunnan, China. In each $20 \mathrm{~m} \times 20 \mathrm{~m}$ plot, our examination focused on species composition of trees via the measure of any trees with $\mathrm{DBH} \geq 4 \mathrm{~cm}$. Importance values were produced from datasets of their relative abundance (RA), relative frequency (RF), and relative prominence (RP). On one hand, we analyzed the composition and geographical affinity of the tree species in Caryota obtusa forests based on the two patterns of geographic distributions (areal-type and natural geographic unit), respectively. On the other hand,
\end{abstract}

收稿日期: 2016-10-05; 接受日期: 2017-05-10

基金项目: 国家自然科学基金(31370228)、美国国家地理协会项目(NGS8288-07)和中国科学院昆明植物研究所东亚植物多样性与生物地理学院重点实 验室开放项目(KLB201205)

* 通讯作者 Author for correspondence. E-mail: ymshui@mail.kib.ac.cn 
we selected the top 5 dominant tree species based on importance value and illustrated their distributions to confirm the position of sampled vegetation in the background of the entire distribution of the target species. The above survey and analysis revealed that there were 67 tree species contained in the sampled vegetation, which was a Caryota obtusa + Streblus macrophyllus community and the geographic affinity of the vegetation belonged to the geographic unit of IndoChina Peninsula with some strong karst background. Our study implies that the vegetation sampled here reached its northernmost distribution and deserves to be prioritized in conservation as it is a biodiversity hotspot in IndoChina Peninsula.

Key words: northernmost tropic; karst valley; palm; relic habitat; tropic vegetation

我国的石灰岩山地主要集中分布于滇黔桂地 区和北部湾地区，为中国重要的植物古特有中心 (应俊生等，1994; 方瑞征等，1995; 吴征镒，1995; Nguyen, 1997)。目前, 特殊生境的生物多样性调查 和研究不断受到人们的关注, 特别是中国南方大面 积的热带石灰岩地区，如近些年石灰岩洞穴有大量 的新物种报道，大大丰富了中国的区系种类(Shui \& Chen, 2005; Chen et al, 2008; 王文采, 2012, 2014)。但针对热带石灰岩山地特有群落类型的调查 和研究相对较少, 仅在广西弄岗和云南西双版纳分 别开展过蚬木(Excentrodendron hsienmu)林和望天 树(Parashorea chinense)林的专项调查和研究, 显示 了石灰岩山地高度的物种多样性和特有性(吴征镒, 1995; 王洪等，1997; Zhu et al, 1998; 王斌等, 2014)。根据我们多年在滇东南石灰岩地带的调查发 现, 董棕(Caryota obtusa)林中存在许多咾钻的新分 类群, 充分显示了其环境的特殊性, 可被视为指示 石灰岩特殊生境的标志性群落。

董棕为单子叶植物棕㭣科的高大“乔木”，高约 10-20 m, 其寿命可达40-50年, 一生仅开一次花, 结实后很快死亡, 被列为国家二级重点保护植物。 董棕生长在石灰岩山地峰从或河谷石灰岩山地较 为陡峭的地段, 多以优势或标志物种出现, 可达乔 木上层, 叶片展开似一把大伞, 树形优美, 在热带 沟谷形成极为独特的植被景观, 如今已广泛作为热 带地区园林绿化的主要树种(图1)。该植物还是热带 地区著名的木本粮食作物, 其茎秆内的提取物富含 淀粉，可制成“西米”，在缅甸和我国云南的独龙江 地区还被制成特色食品—“董棕粉”。在云南麻栗 坡县一带, 董棕花序轴被大量收购以制纤维。董棕 的树干常被砍伐后养殖一种甲虫, 俗称“董棕虫”, 其幼虫可食, 这一习俗可见于云南马关县以及广西 龙州县一带, 故而当地的董棕大树受到了一定程度 的破坏, 致使董棕林面临日益萎缩和消失的危险,

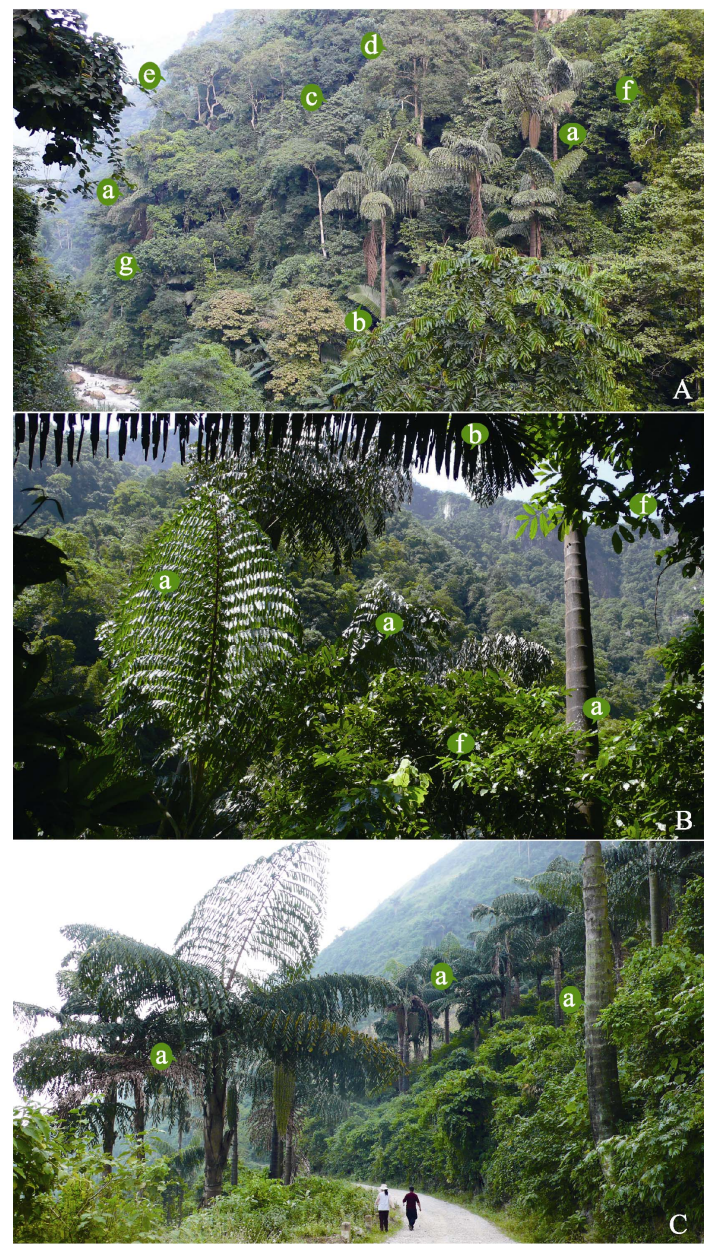

图1 中国红河地区董棕林。A：群落外貌; B: 董棕的树冠; C: 董棕次生纯林。a: 董棕; b: 桄榔; c: 一担柴; d: 网脉核 果木; e: 线毛番龙眼; f: 龙荔。(税玉民摄)

Fig. 1 Caryota obtusa community in the Honghe Region in China. A, The canopy; B, Leaves and trunk of Caryota obtusa; $\mathrm{C}$, The secondary forest dominated by Caryota obtusa. a, Caryota obtusa; b, Arenga westerhoutii; c, Colona floribunda; d, Drypetes perreticulata; e, Pometia tomentosa; f, Dimocarpus confinis. (photographed by Yumin Shui)

其中的一些群落特征物种的数量和分布均受到一 定程度的影响。

目前, 我国的董棕林主要分布于云南贡山经临 沧、西双版纳至绿春、金平、河口至富宁等县, 再 
到广西西南部的那坡、靖西、龙州、凭祥等地，基 本沿广西西南的中越边境至中缅边境一线, 国外主 要分布于印度、斯里兰卡、缅甸、泰国、中南半岛 等地。董棕多生于海拔300-1,600 $\mathrm{m}$ 的石灰岩地区, 少见于石灰岩过渡地区的沟谷雨林。董棕虽然分布 较广, 但同时破坏也很严重, 在中国西南边境, 仅独 龙江、沧源、西盟、绿春、金平、元阳、麻栗坡、 马关、富宁、西畴等地残存小片破坏较小的群落, 其 他地区如西双版纳等已无明显的群落, 而麻栗坡、 个旧等地多是原生植被破坏后残留董棕形成的次 生群落, 云南大围山国家级保护区尚保存着零星几 片以董棕为优势种的原生或半原生群落。原生群落 中董棕的数量并不多, 但因其树冠巨大, 所以比较 醒目。

目前, 有关董棕的研究多集中在保护生物学、 食品化学等方面 (Everett, 1995; Wijeyaratne \& Jayathilake, 2000), 国内外尚未有董棕林研究的专 类报道, 仅在一些植被论文中有董棕的记录, 其均 生长在石灰岩山地的环境, 并且其所生长的原生群 落结构和物种多样性极为丰富(Huang et al, 1999)。 然而, 系统的董棕群落的研究仍极缺乏, 《云南植 被》、《中国植被》等植被专著均未见有记载(吴征镒 和朱彦承, 1987; 吴征镒, 1995), 无法有效指导我国 喀斯特地区董棕林的研究和保护工作。为此, 我们 在中国董棕分布最为集中和最为典型的地段-— 云南东南部的大围山地区开展了董棕林的调查和 研究, 以服务于今后系统而全面的董棕生物多样性 研究和保护工作。

\section{1 材料与方法}

\section{1 研究区概况}

研究地区位于云南省东南部的个旧市绿水河 $\left(23^{\circ} 01^{\prime} \mathrm{N}, 103^{\circ} 24^{\prime} \mathrm{E}\right)$, 属于云南大围山国家级自然
保护区，蒙新高速公路从中间穿过，旁边悬崖上高 大的董棕林蔚为壮观 (图 $1 \mathrm{~A}, \mathrm{~B}$ )。绿水河为海拔 400-1,000 m的喀斯特峡谷, 受人为影响较小, 尤其 在400-800 m地段仍保存着较为完整的北热带石灰 岩季雨林。董棕群落集中分布于绿水河及其邻近几 个峡谷海拔 400-1,300 $\mathrm{m}$ 的河谷陡峭的喀斯特峡谷 一侧, 坡度一般在 30 以上, 地面岩石裸露率 $60 \%$ 以 上, 其中在 $1,000 \mathrm{~m}$ 以上接近村寨或公路的部分地 段董棕几呈单优状态(图1C), 目前已被当地林业部 门辟为市级保护区。

\section{2 样地调查}

在绿水河东坡的海拔300-800 m范围, 选择了 6 个 $20 \mathrm{~m} \times 20 \mathrm{~m}$ 的标准样地进行调查(表1)。对乔木层 进行每木检测, 对胸径 $(\mathrm{DBH}) \geq 4 \mathrm{~cm}$ 的植株测量其 树高、胸径、冠幅、物候等, 并采集对应的凭证标 本, 标本保存在中国科学院昆明植物研究所标本馆 $(\mathrm{KUN})$ 。其中, 对群落中的树状棕榈科植物作为乔 木树种进行了重点调查, 如董棕和桄榔 (Arenga westerhoutii)。

\section{3 数据分析}

通过6个典型样方的设置, 分别整理出乔木层 的种类组成及其重要值。其中, 乔木层重要值(IV) 采用以下公式计算: (相对密度+相对显著度+相对频 度) $/ 3 \times 100 \%$ ，显著度以胸径为依据(宋永昌, 2001)。 乔木树种的地理分布采用以下 3 个方面的数据进行 分析: (1)分布区类型(吴征镒等, 2006); (2)围绕研究 地点, 分别采用亚洲和滇东南两个尺度进行分析; (3)选择重要值排名前 5 位的树种, 通过全球生物多 样性信息网络(GBIF, http://www.gbif.org/)等数据库 获得其主要分布信息, 构建其地理分布图。通过以 上3组数据的比较分析, 确定研究区董棕林的地理 分布特点和区系亲缘。所有分析和作图采用Excel 2010、DIVA-GIS 7.5.0和Photoshop CS等软件完成。

表1 云南红河地区6个董棕林样方的生境特点及物种数量组成

Table 1 Habitat information and species composition in six plots of Caryota obtusa forests in the Honghe region of Yunnan, SW China

\begin{tabular}{|c|c|c|c|c|c|c|c|c|c|c|}
\hline $\begin{array}{l}\text { 编号 } \\
\text { No. }\end{array}$ & $\begin{array}{l}\text { 海拔 } \\
\text { Altitude (m) }\end{array}$ & $\begin{array}{l}\text { 坡向 } \\
\text { Aspect }\end{array}$ & $\begin{array}{l}\text { 坡度 } \\
\text { Slope Degree }\end{array}$ & $\begin{array}{l}\text { 高度 } \\
\text { Height (m) }\end{array}$ & $\begin{array}{l}\text { 总盖度 } \\
\text { Coverage (\%) }\end{array}$ & $\begin{array}{l}\text { 乔木 } \\
\text { Tree }\end{array}$ & $\begin{array}{l}\text { 灌木 } \\
\text { Shrub }\end{array}$ & $\begin{array}{l}\text { 草本 } \\
\text { Herb }\end{array}$ & $\begin{array}{l}\text { 藤本 } \\
\text { Vine }\end{array}$ & $\begin{array}{l}\text { 附生植物 } \\
\text { Epiphyte }\end{array}$ \\
\hline G01 & 560 & $\mathrm{NW} 42^{\circ}$ & $33^{\circ}$ & 26 & 80 & 16 & 44 & 18 & 14 & 9 \\
\hline G02 & 550 & $\mathrm{NW} 30^{\circ}$ & $25^{\circ}$ & 27 & 70 & 19 & 47 & 23 & 18 & 9 \\
\hline G03 & 560 & $\mathrm{NE}^{\circ} 0^{\circ}$ & $36^{\circ}$ & 35 & 75 & 19 & 39 & 39 & 16 & 7 \\
\hline G04 & 570 & NE38 $8^{\circ}$ & $41^{\circ}$ & 24 & 75 & 21 & 28 & 11 & 11 & 1 \\
\hline G10 & 860 & $\mathrm{NE} 2^{\circ}$ & $39^{\circ}$ & 22 & 66 & 22 & 60 & 37 & 34 & 8 \\
\hline G11 & 510 & $\mathrm{NW} 23^{\circ}$ & $14^{\circ}$ & 32 & 86 & 34 & 34 & 40 & 19 & 8 \\
\hline
\end{tabular}




\section{2 结果}

\section{1 董棕林的种类组成}

在调查的 6 个样方中, 乔木层共调查到 67 种, 隶属于 31 科 56 属, 其中单子叶植物仅棕榈科的董棕 及桄榔 2 种(表 2 )。重要值排名前 5 位的分别为双果桑 (Streblus macrophyllus, $I V=13.13)$ 、董棕 $(I V=8.94)$, 桄榔 $(I V=6.22)$ 、一担柴 (Colona floribunda, $I V=4.21)$ 和网脉核果木(Drypetes perreticulata, $I V=3.74$ ) (图 1)。其中，仅董棕和网脉核果木处于乔木的上层， 为严格的嗜钙植物。因此, 我们初步确定该植被 为董棕+双果桑群落(Caryota obtusa + Streblus macrophyllus community), 属于北热带石灰岩季 雨林。

\section{2 乔木树种的地理联系}

根据董棕群落样方中乔木层物种的区系地理 成分分析(附录1; Wu et al, 2006), 中国至中南半岛 分布类型(VII-4)和中国特有分布类型 $(X V)$ 最多, 分 别达到全部种数的 $20.90 \%$, 而热带亚洲至热带大洋 洲分布类型 $(\mathrm{V})$ 、中国至热带亚洲分布类型 $(\mathrm{VII}-3)$ 及中国-喜马拉雅分布类型(XIV-SH)最少，仅分别 占全部种数的 $2.99 \%$ (图2)。

而从中国分布与周边地区的关系看, 中国至中 南半岛分布最多，中国至热带亚洲分布最少(图 $3 \mathrm{~A})$ 。通过中国至中南半岛分布的进一步分析看出, 在滇东南辐射至周边地区的分布中也以滇东南至 中南半岛的分布区类型最多，其次为滇东南至广 西、越南分布，而滇东南至华中地区的类型最少

表2 中国红河地区董棕林群落主要乔木树种组成及其重要值

Table 2 Main tree species and their importance values in Caryota obtusa forest in the Honghe region, SW China

\begin{tabular}{|c|c|c|c|c|c|}
\hline 科 Family & 物种 Species & $\begin{array}{l}\text { 相对多度 } \\
\text { Relative } \\
\text { abundance }\end{array}$ & $\begin{array}{l}\text { 相对显著度 } \\
\text { Relative } \\
\text { frequency }\end{array}$ & $\begin{array}{l}\text { 相对频度 } \\
\text { Relative } \\
\text { prominence }\end{array}$ & $\begin{array}{l}\text { 重要值 } \\
\text { Importance } \\
\text { values }\end{array}$ \\
\hline 桑科 Moraceae & 双果桑 Streblus macrophyllus & 0.2394 & 0.1087 & 0.0458 & 13.13 \\
\hline 棕㭣科 Palmae & 董棕 Caryota obtusa & 0.0664 & 0.1559 & 0.0458 & 8.94 \\
\hline 棕㭣科 Palmae & 桄榔 Arenga westerhoutii & 0.0704 & 0.0931 & 0.0229 & 6.22 \\
\hline 椴树科 Tiliaceae & 一担柴 Colona floribunda & 0.0423 & 0.0382 & 0.0458 & 4.21 \\
\hline 大戟科 Euphorbiaceae & 网脉核果木 Drypetes perreticulata & 0.0262 & 0.0555 & 0.0305 & 3.74 \\
\hline 无患子科 Sapindaceae & 干果木 Xerospermum bonii & 0.0221 & 0.0659 & 0.0229 & 3.7 \\
\hline 苏木科 Caesalpiniaceae & 中国无忧花 Saraca dives & 0.0322 & 0.0502 & 0.0229 & 3.51 \\
\hline 菖麻科 Urtiaceae & 圆基火麻树 Dendrocnide basirotunda & 0.0362 & 0.0296 & 0.0305 & 3.21 \\
\hline 大戟科 Euphorbiaceae & 棒柄花 Cleidion brevipetiolatum & 0.0443 & 0.0150 & 0.0305 & 2.99 \\
\hline 番荔枝科 Annonaceae & 金平藤春 Alphonsea boniana & 0.0221 & 0.0159 & 0.0382 & 2.54 \\
\hline 柿树科 Ebenaceae & 六花柿 Diospyros hexamera & 0.0141 & 0.0233 & 0.0305 & 2.26 \\
\hline 大戟科 Euphorbiaceae & 粗糠柴 Mallotus philippensis & 0.0443 & 0.0141 & 0.0076 & 2.2 \\
\hline 梧桐科 Sterculiaceae & 苹婆 Sterculia monosperma & 0.0221 & 0.0254 & 0.0153 & 2.09 \\
\hline 番荔枝科 Annonaceae & 海南澄广花 Orophea hainanensis & 0.0342 & 0.0108 & 0.0153 & 2.01 \\
\hline 夹竹桃科 Apocynaceae & 胭木 Wrightia arborea & 0.0161 & 0.0149 & 0.0229 & 1.8 \\
\hline 无患子科 Sapindaceae & 线毛番龙眼 Pometia tomentosa & 0.0080 & 0.0268 & 0.0153 & 1.67 \\
\hline 大戟科 Euporbiaceae & 大麻叶巴豆 Croton damayeshu & 0.0121 & 0.0140 & 0.0153 & 1.38 \\
\hline 肉豆冦科 Myristicaceae & 大叶风吹楠 Horsfieldia kingii & 0.0141 & 0.0114 & 0.0153 & 1.36 \\
\hline 冬青科 Aquifoliaceae & 阔叶冬青 lex latifrons & 0.0101 & 0.0201 & 0.0076 & 1.26 \\
\hline 紫金牛科 Myrsinaceae & 星毛紫金牛 Ardisia nigropilosa & 0.0161 & 0.0057 & 0.0153 & 1.23 \\
\hline 无患子科 Sapindaceae & 龙荔 Dimocarpus confinis & 0.0080 & 0.0028 & 0.0229 & 1.13 \\
\hline 蝶形花科 Papilionaceae & 红豆属一种 Ormosia sp. & 0.0121 & 0.0053 & 0.0153 & 1.09 \\
\hline 木兰科 Magoniaceae & 单性木兰 Kmeria septentrionalis & 0.0080 & 0.0161 & 0.0076 & 1.06 \\
\hline 紫葳科 Bignoniaceae & 火烧花 Mayodendron igneum & 0.0060 & 0.0026 & 0.0229 & 1.05 \\
\hline 桑科 Moraceae & 苹果榕 Ficus oligodon & 0.0080 & 0.0076 & 0.0153 & 1.03 \\
\hline 楝科 Meliaceae & 溪杪 Chisocheton cumingianus & 0.0060 & 0.0017 & 0.0229 & 1.02 \\
\hline
\end{tabular}




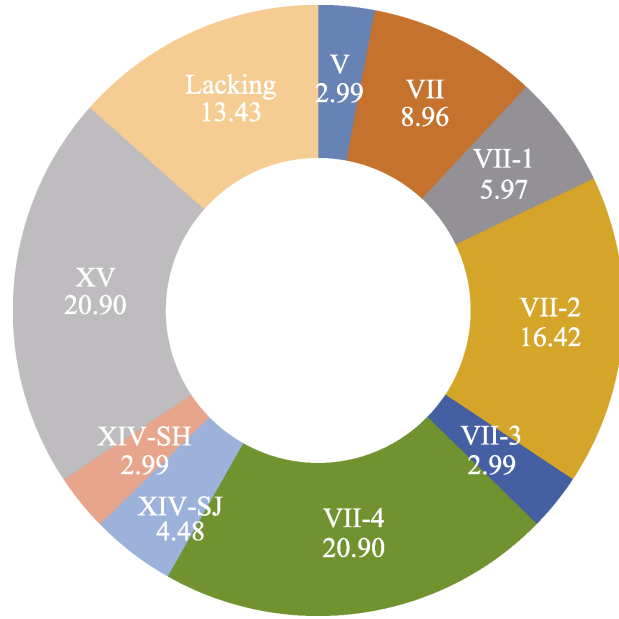

- V. 热带亚洲至热带大洋洲分布

Trop. Asia to Trop. Australasia Oceania

VII. 热带亚洲(印度一马来)分布

Trop. Asia = Trop. SE. Asia + Indo-Malaya + Trop. S \& SW Pacific Is1

VII-1. 爪哇(或苏门答腊)、喜马拉雅间断或星散分布至华南、西南 Java or Sumatra, Himalaya to S, SW China disjuncted or diffused

VII-2. 热带印度至华南(尤其云南南部)分布

Trop. India to S China (especially S Yunnan)

- VII-3. 缅甸、泰国至华南(或西南)分布

Myanmar, Thailand to SW China

VII-4. 越南(或中南半岛)至华南(或西南)分布

Vietnam or IndoChina Peninsula to S or SW China

- XIV-SJ. 中国-日本 Sino-Japan

XIV-SH. 中国-喜马拉雅 Sino-Himalaya

- XV. 中国特有分布 Endemic to China

数据缺失 Data lacking

图2 中国红河地区董棕林乔木层树种的种分布区类型组成(\%)

Fig. 2 Composition (\%) of area-type of the tree species in Caryota obtusa community in the Honghe region, SW China

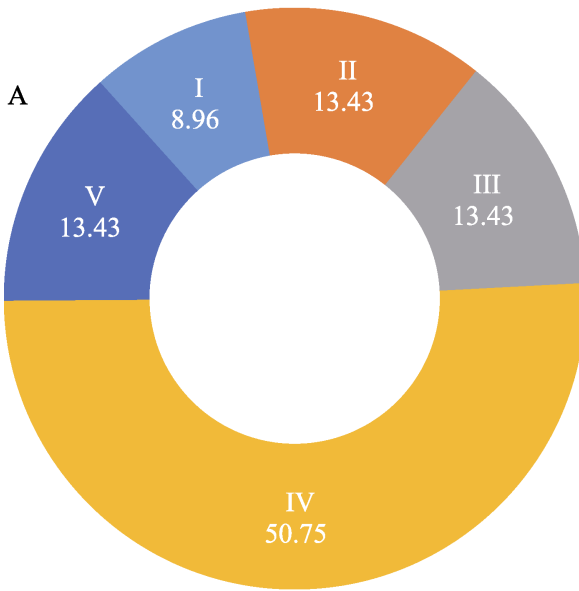

II. 中国-热带亚洲分布 China-Tropical Asia

III. 中国-热带东南亚 China-SE Tropical Asia

nIII. 中国-喜马拉雅分布 China-Himalaya

IV. 中国-中南半岛分布 China-Indochina

口V. 数据缺失 Data lacking
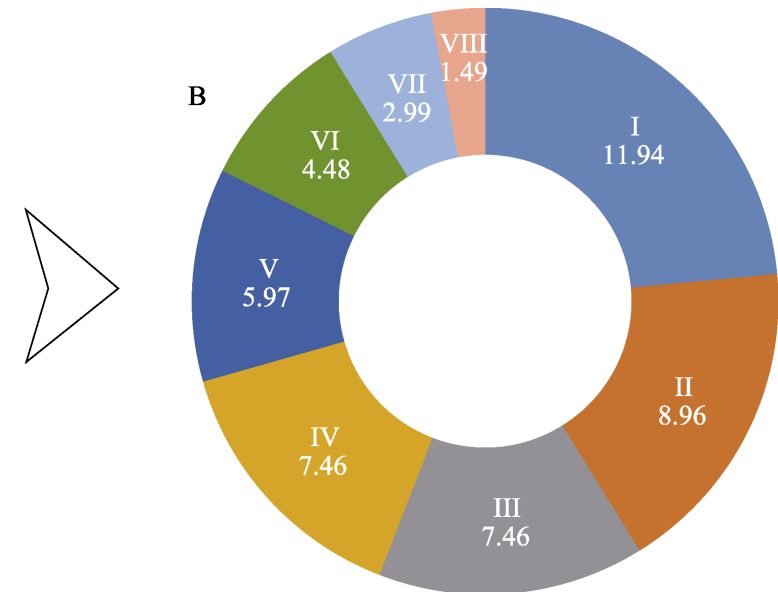

E I. 滇东南-中南半岛分布 SE Yunnan-IndoChina Peninsula

III. 滇东南-广西、越南分布 SE Yunnan-Guangxi \& Vietnam

- III. 滇东南一广西分布 SE Yunnan-Guangxi

IV. 滇东南特有分布 SE Yunnan

v V. 滇东南-滇南、滇西南分布 SE Yunnan-S \& SW Yunnan

- VI. 滇东南-越南、日本分布 SE Yunnan-Vietnam \& Japan

- VII. 滇东南-越南分布 SE Yunnan-Vietnam

VIII. 滇东南-中国中部分布 SE Yunnan-C China

图3 中国西南喀斯特地区董棕林乔木层树种的种地理联系分析。(A)与中国分布联系的大尺度地理成分; (B)与滇东南分布联 系的小尺度地理成分。

Fig. 3 Composition of the geographical elements of the tree species in Caryota obtusa community in SW China. (A) The large-scale geographic elements related to China; (B) The small-scale geographic elements related to southeast Yunnan (SE Yunnan).

(图3B)。可见, 以云南东南部为代表的我国西南董 棕林乔木树种以中南半岛和中国交界地区为其分 布的核心地区。

\section{3 优势或建群种的地理分布}

董棕群落样方中有 5 种占优势的乔木树种, 分 别为双果桑、董棕、桄榔、一担柴、网脉核果木。 其中, 仅董棕和网脉核果木处于乔木的上层, 双果
桑虽仅处于乔木下层及灌木层但个体数量最多。这 些优势种中，以董棕分布最广，从热带北缘分布至 热带马来半岛，其次是双果桑，分布稍广，其他显 著度较高的优势种分布范围均较董棕要小，并且集 中分布在中南半岛, 个别辐射到印度西北部、马来 半岛和菲律宾(图4), 一定程度显示出该群落的北热 带性质。 


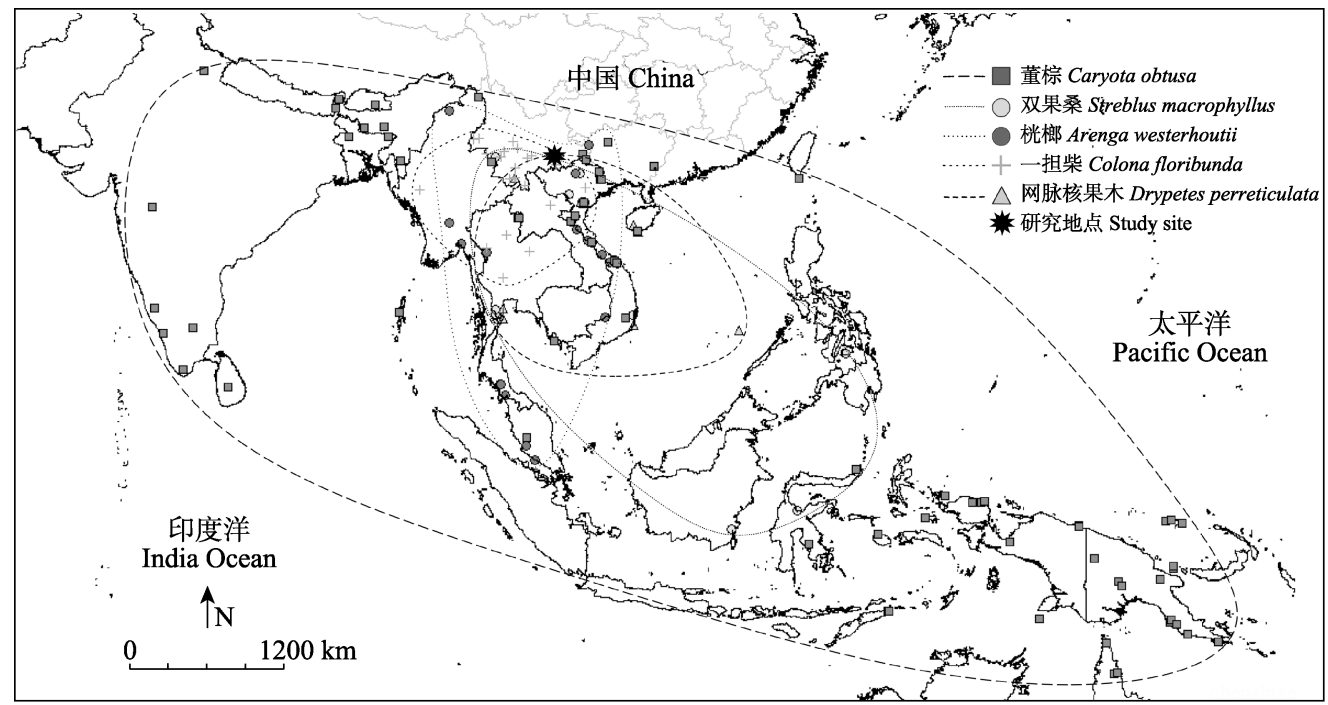

图4 中国喀斯特地区董棕林主要建群树种的地理分范围(基于表2乔木层的重要值排名)

Fig. 4 The distribution of the five dominant trees of Caryota obtusa forests based on the order of importance values (IV) in the Honghe region, China (from Table 2). The aster indicates the plot sites in the this research.

\section{3 讨论}

\section{1 我国西南喀斯特地区董棕林应与中南半岛属} 同一个自然区系地理单元

我们报道了中国西南董棕林的乔木树种组成, 在面积约 $3.00 \mathrm{~km}^{2}$ 的 6 个 $400 \mathrm{~m}^{2}$ 样方中共记录乔木 层树种67种, 并确定了它们各自的重要值和该群落 的群系名称, 即董棕+双果桑群落。进一步通过乔木 层植物的地理成分分析, 发现研究地区的董棕林不 仅与云南 (中南半岛)至华南 (西南) 密切相关 (20.90\%), 更具有中国特有分布的成分 $(20.90 \%)$, 显示该地区既有中南半岛的区系背景, 也具有其独 特的地理成分, 暗示该地区较为古老和稳定的区系 特点(图2,3)。通过群落优势树种具体分布点的比较 分析发现, 该区域地处董棕林分布区的最北端, 初 步显示了中国西南喀斯特植被可能的热带北缘性 质(图4)。作为棕榈科能形成群落优势的物种之一, 董棕群落的现有分布界限及其物种组成可能反应 了地质历史过程中欧亚大陆和热带东南亚喀斯特 地区的陆相和海相的潜在联系(Hahn \& Sytsma, 1999)。可见，董棕林独特的物种多样性在亚洲热带 喀斯特地区的生态系统及其历史变迁中占据着极 为独特的地位, 其深入的生物地理学研究将为揭示 中国及中南半岛的区系地理联系提供广阔的研究 前景。

\section{2 喀斯特地区植被乔木树种丰富，群落类型丰}

\section{富, 片断化明显}

董棕林的乔木优势树种明显不同于同一气候 带的喀斯特其他石灰岩季雨林的树种组成。在广西 弄岗的喀斯特季节性雨林中, 优势树种为闭花木 (Cleistanthus sumatranus)、苹婆(Sterculia monosperma)、广西牡荆(Vitex kwangsiensis)、蚬木、海南 椴(Diplodiscus trichosperma)、劲直刺桐(Erythrina stricta) 和海南大风子(Hydnocarpus hainanensis) 等 (王献溥等，1997; 王斌等，2014)，几乎完全不同于 上述董棕林的优势树种。在西双版纳的石灰岩季雨 林中，优势树种是线毛番龙眼 (Pometia tomentosa)、 藤春(Alphonsea monogyna)、铁灵花(Celtis philippensis var. wightii)、轮叶戟(Lasiococca comberi var. pseudoverticillata)等, 除了沟谷广布的线毛番龙眼 外，其他的优势树种几乎都不同(Zhu et al, 1998)。 可见，喀斯特地区的植被物种组成在不同地区和生 境上显示出极大的差异性，特别是在不同属的等级 上，也暗示了热带喀斯特地区生态系统物种多样性 的复杂性。因此，喀斯特地区植被的多样性调查需 要更为密集的取样才能客观地反映其物种多样性 的全貌。

致谢: 感谢中国科学院昆明植物研究所的魏志丹、 赵厚涛，云南绿水河电站的王万达等多位同志在野 
外工作中的大力支持和配合。此外, 昆明植物研究 所的陈力在作图准备中也提供了协助。

\section{参考文献}

Chen WH, Moller M, Shui YM, Zhang MD (2008) A new species of Paraboea (Gesneriaceae) from a karst cave in Guangxi, China, and observations on variations in flower and inflorescence architecture. Botanical Journal of the Linnean Society, 158, 681-688.

Everett Y (1995) The kitul palm: ethnobotany of Caryota urens L. in highland Sri Lanka. Journal of Ethnobiology, 15, 161176.

Fang RZ, Bai PY, Huang GB, Wei YG (1995) A floristic study on the seed plants from tropics and subtropics of DianQian-Gui. Acta Botanica Yunnanica, (Suppl. VII), 111-150. (in Chinese with English abstract) [方瑞征, 白佩瑜, 黄广 宾, 韦毅刚 (1995) 滇黔桂热带亚热带(滇黔桂地区和北 部湾地区)种子植物区系研究. 云南植物研究, (增刊VII), 111-150.]

Hahn WJ, Sytsma KJ (1999) Molecular systematics and biogeography of the Southeast Asian genus Caryota (Palmae). Systematic Botany, 24, 558-580.

Huang SH, Chen CJ, Shui YM, Li QR (1999) A study on the ecology and floristic composition of Cycas multipinnata community. In: Biology and Conservation of Cycads-Proceedings of the Fourth International Conference on Cycad Biology (ed. Chen CJ), pp. 41-49. International Academic Publishers, Beijing.

Nguyen NT (1997) The vegetation of Cucphuong National Park, Vietnam. Sida, 17, 719-759.

Shui YM, Chen WH (2005) New data of sect. Coelocentrum in Begoniaceae. Acta Botanica Yunnanica, 27, 355-374.

Song YC (2001) Vegetation Ecology. East China Normal University Press, Shanghai. (in Chinese) [宋永昌 (2001) 植被 生态学. 华东师范大学出版社, 上海.]

Wang B, Huang YS, Li XK, Xiang WS, Ding T, Huang FZ, Lu SH, Han WH, Wen SJ, He LJ (2014) Species composition and spatial distribution of a 15 ha northern tropical karst seasonal rain forest dynamics plot in Nonggang, Guangxi, Southern China. Biodiversity Science, 22, 141-156. (in Chinese with English abstract) [王斌, 黄俞淞, 李先琨, 向 悟生, 丁涛, 黄甫昭, 陆树华, 韩文衡, 文淑均, 何兰军 (2014) 弄岗北热带喀斯特季节性雨林 15 ha监测样地的树 种组成与空间分布. 生物多样性, 22, 141-156.]
Wang H, Zhu H, Li BG (1997) Vegetation of limestone in Xishuangbanna Southwest China. Guihaia, 17, 101-117. (in Chinese with English abstract) [王洪, 朱华, 李保贵 (1997) 西双版纳石灰岩森林植被.广西植物, 17, 101-117.]

Wang WT (2012) Two new series and eight new species of Elatostema (Urticaceae) from Yunnan. Guihaia, 32, 427435. [王文采 (2012) 云南楼梯草属二新系和八新种. 广 西植物, 32, 427-435.]

Wang WT (2014) Elatostema (Uriticacea) in China. Qingdao Publishing House, Qingdao. [王文采 (2014) 中国楼梯草 属植物. 青岛出版社, 青岛.]

Wang XP, Sun SZ, Li XX (1998) Study of limestone seasonal rain forest classification in Guangxi. Bulletin of Botanical Research, 18, 428-460. (in Chinese with English abstract) [王献溥, 孙世洲, 李信贤 (1998) 广西石灰岩季节性雨 林分类的研究. 植物研究, 18, 428-460.]

Wijeyaratne SC, Jayathilake AN (2000) Characteristics of two yeast strains (Candida tropicalis) isolated from Caryota urens (Kithul) Toddy for single cell protein production. Journal of National Science Foundation of Sri Lanka, 28, 79-86.

Wu ZY (1995) Vegetation of China, pp. 376-379. Science Press, Beijing. (in Chinese) [吴征镒 (1995) 中国植被, 376-379页. 科学出版社, 北京.]

Wu ZY, Zhou ZK, Sun H, Li DZ, Peng H (2006) The Areal-Types of Seed Plants and Their Origin and Differentiation. Yunnan Science \& Technology Press, Kunming. (in Chinese) [吴征镒, 周浙昆, 孙航, 李德铢, 彭华 (2006) 种子植物分布区类型及其起源与分化. 云南科技出版社, 昆明.]

Wu ZY, Zhu YC (1987) Vegetation of Yunnan, pp. 188-192. Science Press, Beijing. (in Chinese) [吴征镒, 朱彦承 (1987) 云南植被, 188-192页. 科学出版社, 北京.]

Ying JS, Zhang YL, Boufford DE (1994) Endemic Genera of Seed Plants in China. Science Press, Beijing. (in Chinese) [应俊生, 张玉龙, Boufford DE (1994) 中国种子植物特有 属. 科学出版社, 北京.]

Zhu H, Wang H, Li BG (1998) The structure, species composition and diversity of the limestone vegetation in Xishuangbanna, SW China. Gardens Bulletin Singapore, 50, 5-33.

(责任编辑：黄祥忠)

\section{附录 Supplementary Material}

附录1 中国西南红河地区董棕林的乔木树种组成

Appendix 1 Tree species composition of Caryota obtusa forests in the Honghe region, SW China http://www.biodiversity-science.net/fileup/PDF/2016289-1.pdf 
陈文红, 施济普, 文军, 郭世伟, 常艳芬, 税玉民. 中国红河地区董棕林乔木树种的物种组成和地理亲缘关 系. 生物多样性, 2017, 25 (8): 823-829.

http://www.biodiversity-science.net/CN/10.17520/biods.2016289

附录1 中国西南红河地区董棕林的乔木树种组成。中国西南董棕林群落乔木层树种共67种(包括59个明确 的种类和 8 个不明确的种类, 所有标本凭证存于中国科学院昆明植物研究所标本馆, KUN)

Appendix 1 Compositionof the tree species Caryota obtusa forests in the Honghe region, SW China. Total 67 species of the tree species including 59 known species and 8 unknown species. All the above vouchers deposited in KUN (Herbarium of Kunming Institute of Botany, Chinese Academy of Sciences)

\begin{tabular}{|c|c|c|c|}
\hline 编号 No. & 树种 Tree species & 编号 No. & 树种 Tree species \\
\hline 1 & 水团花 Adina pilulifera & 35 & 云南风吹楠 Horsfieldia prainii \\
\hline 2 & 曲梗崖摩 Aglaia spectabilis & 36 & 阔叶冬青 Ilex latifrons \\
\hline 3 & 香楠 Aidia canthioides & 37 & 单性木兰 Kmeria septentrionalis \\
\hline 4 & 金平藤春 Alphonsea boniana & 38 & 灰岩血桐 Macaranga esquirolii \\
\hline 5 & 山楝 Aphanamixis polystachya & 39 & 粗糠柴 Mallotus philippensis \\
\hline 6 & 糙叶树 Aphananthe aspera & 40 & 野桐属一种 Mallotus sp. \\
\hline 7 & 星毛紫金牛 Ardisia nigropilosa & 41 & 火烧花 Mayodendron igneum \\
\hline 8 & 酸苔菜 Ardisia solanacea & 42 & 肿轴野独活 Miliusa baillonii \\
\hline 9 & 桄榔 Arenga westerhoutii & 43 & 红豆树属一种 Ormosia sp. \\
\hline 10 & 禾串树 Bridelia balansae & 44 & 海南澄广花 Orophea hainanensis \\
\hline 11 & 董棕 Caryota obtusa & 45 & 望天树 Parashorea chinensis \\
\hline 12 & 溪杪 Chisocheton cumingianus & 46 & 大䒓楠 Phoebe megacalyx \\
\hline 13 & 南酸苯 Choerospondias axillaris & 47 & 线毛番龙眼 Pometia pinnata \\
\hline 14 & 云南黄皮 Clausena harmandiana & 48 & 截裂翅子树 Pterospermum truncatolobatum \\
\hline 15 & 棒柄花 Cleidion brevipetiolatum & 49 & 芸香科一种 Rutaceae sp. \\
\hline 16 & 一担柴 Colona floribunda & 50 & 无患子科一种 Sapindaceae sp. \\
\hline 17 & 大麻叶巴豆 Croton damayeshu & 51 & 南酸㱑属一种 Sapindus sp. \\
\hline 18 & 丛花厚壳桂 Cryptocarya densiflora & 52 & 中国无忧花 Saraca dives \\
\hline 19 & 贫花厚壳桂 Cryptocarya depauperata & 53 & 铁榄 Sinosideroxylon pedunculatum \\
\hline 20 & 圆基火麻树 Dendrocnide basirotunda & 54 & 苹婆 Sterculia monosperma \\
\hline 21 & 龙荔 Dimocarpus confinis & 55 & 基苹婆 Sterculia principis \\
\hline 22 & 六花柿 Diospyros hexamera & 56 & 双果桑 Streblus macrophyllus \\
\hline 23 & 黑皮柿 Diospyros nigricortex & 57 & 乌楣 Syzygium cumini \\
\hline 24 & 辛果漆 Drimycarpus racemosus & 58 & 阔叶蒲桃 Syzygium megacarpum \\
\hline 25 & 网脉核果木 Drypetes perreticulata & 59 & 蒲桃属一种 Syzygium sp. \\
\hline 26 & 长果土楠 Endiandra dolichocarpa & 60 & 云南瑤椒树 Tapiscia yunnanensis \\
\hline 27 & 火绳树 Eriolaena spectabilis & 61 & 白皮乌口树 Tarenna depauperata \\
\hline 28 & 大戟科一种 Euphorbiacea & 62 & 岭罗麦 Tarennoidea wallichii \\
\hline 29 & 歪叶榕 Ficus cyrtophylla & 63 & 吴茱英属一种 Tetradium sp. \\
\hline 30 & 苹果榕 Ficus oligodon & 64 & 刺通草 Trevesia palmata \\
\hline 31 & 大叶刺篱木 Flacourtia rukam & 65 & 翼核果 Ventilago leiocarpa \\
\hline 32 & 华山小桔 Glycosmis pseudoracemosa & 66 & 胭木 Wrightia arborea \\
\hline 33 & 山龙眼属一种 Helicia sp. & 67 & 干果木 Xerospermum bonii \\
\hline 34 & 大叶风吹楠 Horsfieldia kingii & & \\
\hline
\end{tabular}

